\title{
A new p21 waf1/cip1 isoform is an early event of cell response to oxidative stress
}

\author{
Franca Esposito', Franca Cuccovillo', Lucia Russo', \\ Francesca Casella ${ }^{1}$, Tommaso Russo ${ }^{1}$ and \\ Filiberto Cimino ${ }^{1,2}$ \\ ${ }^{1}$ Dipartimento di Biochimica e Biotecnologie Mediche, Università di Napoli \\ 'Federico II', Via Pansini 5, 80131, Naples, Italy \\ ${ }^{2}$ corresponding author: F. Cimino, Dipartimento di Biochimica e Biotecnologie \\ Mediche, Università degli Studi di Napoli Federico II, Via Pansini 5, I-80131, \\ Napoli, Italy. tel: +39 81 7464966, fax: +39 817463650 ; \\ e-mail: cimino@dbbm.unina.it
}

Received 2.3.98; revised 1.6.98; accepted 12.6.98

Edited by B.A. Osborne

\begin{abstract}
p21 waf1/cip1 mRNA and protein accumulate in intact cells exposed to oxidizing agents through a p53-independent, MAPK-dependent mechanism. Treatment with oxidizing agents also yields a second form of this protein (FM p21), characterized by a faster migration on SDS-PAGE. This phenomenon depends on the modification of intracellular redox conditions induced by diethylmaleate, a glutathionedepleting agent, being prevented by the pretreatment with the glutathione precursor $\mathrm{N}$-acetylcysteine. The appearance of this FM p21 form is very early, being observed 5 min after exposure to diethylmaleate, long before the already observed accumulation of p21 induced by oxidative stress. Furthermore, experiments with dominant negative mutants of MEK demonstrate that, in contrast with that observed for the oxidative stress-induced accumulation of p21 mRNA and protein, the appearance of FM p21 form is not dependent from the activation of the MAPK pathway.

It was previously observed (Tchou et al, 1996) that in some lung carcinoma cells long exposure to high doses of phorbol esters also induces the appearance of a faster-migrating p21 electrophoretic band and it was suggested that this could result from a different phosphorylation or from a proteolytic processing at the $\mathrm{C}$-terminus of the protein. The latter is not the case for the diethylmaleate-induced FM p21 whose $\mathrm{C}$-terminus is intact, as demonstrated by the expression of a C-terminus tagged p21 cDNA. On the contrary, the observed migration shift seems to be dependent on the hypophosphorylation of the protein; in fact, a pretreatment of cells with okadaic acid, an inhibitor of (serine/threonine) phosphatases, inhibits the oxidation-dependent appearance of the FM p21 and the block of protein synthesis, caused by cycloeximide, does not affect the appearance of FM p21, that thus could derive from the dephosphorylation of preexisting protein.
\end{abstract}

Keywords: p21 waf1/cip1; oxidative stress; cell cycle; phosphatases
Abbreviations: FM, faster-migrating p21 form; DEM, diethylmaleate; GSH, reduced glutathione; DMEM, Dulbecco's modified Eagle's medium; HA, hemoagglutinin; NAC, N-acetylcysteine; TPA, 12-O-tetradecanoyl-phorbol 13-acetate; OA, okadaic acid; MAPK, mitogen-activated protein kinase; MEK, mitogen-activated protein kinase kinase; PAGE, polyacrylamide gel electrophoresis

\section{Introduction}

p2 $1^{\text {waf1/cip } 1}$ gene encodes a protein that is a potent inhibitor of cyclin-dependent kinases (Harper et al, 1993; El-Deiry et al, 1993; Xiong et al, 1993). The inhibition of cyclin-CDK complexes, by interfering with phosphorylation events which are critical for cell cycle transitions, is responsible for the regulation of G1-S transition (Xiong et al, 1993). In addition to the well-defined aminoterminal cyclin- and CDK-binding motifs (Chen et al, 1995; Chen J et al, 1996), a binding site for the proliferating cell nuclear antigen (PCNA) is present at the C-terminus of p21 protein (Gulbis et al, 1996). Through this interaction, p21 inhibits PCNA-dependent DNA replication (Flores-Rozas et al, 1994) while the DNA-repair function is not inhibited (Li R et al, 1994). p21 gene transcription is under the control of p53, therefore, following DNA damage, the induction of p53 activates the transcription of the p21 gene and in turn the accumulation of its product; as a result of this accumulation a cell growth arrest is induced (El-Deiry et al, 1994).

Several p53-independent inducers of p21 have been described. These include stimulation with serum and growth factors, treatment with phorbol esters and growth factors, exposure to cytokines such as IL6, interferon $\gamma$ and others (Michieli et al, 1994; Saeed Sheikh et al, 1994; Macleod et al, 1995; Zeng and El-Deiry, 1996; Lieberman et al, 1995). These agents induced p21 mRNA and protein accumulation in cells lacking a functional p53 and, probably, they work by activating different pathways. All these results support the hypothesis that p21 is not only a mediator of p53-induced growth arrest following DNA damage, but it also works as a regulator of the G1->S transition as a consequence of different physiological conditions.

Diethylmaleate (DEM), a glutathione (GSH)-depleting agent, decreases intracellular GSH concentration, by a GSH-transferase catalyzed reaction (Plummer et al, 1981); consequently, there is an increase of the intracellular levels of reactive oxygen species with an alteration of the conditions which keep many molecules in the proper reduced state (for a review see Cimino et al, 1997). We demonstrated that the exposure to DEM of different cell lines causes an impairment of p53 activity by abolishing its DNA-binding efficiency (Russo et al, 1995). However, following DEM treatment cells undergo cell cycle arrest and this is dependent on the DEM-induced accumulation of 
p21 mRNA and protein. This phenomenon was also observed in cell lines lacking a functional p53 gene, therefore it is regulated by a p53-independent pathway (Russo et al, 1995), that we demonstrated recently to require the activation of the ras-MAPK cascade (Esposito et al, 1997).

Herein we describe that a very early event of the cellular response to the modification of intracellular redox conditions towards an oxidizing environment provoked by DEM is the appearance of a new p21 form, which shows a faster migration rate on SDS-PAGE. This event is completely distinct from the already described accumulation of p21 following the exposure of the cells to DEM, both for the timing and for the molecular mechanisms responsible for its appearance.

\section{Results and discussion}

We previously demonstrated that the treatment of cell lines with DEM, a glutathione-depleting agent, leads to the accumulation of p21 mRNA and protein, through the activation of a p53-independent mechanism (Russo et al, 1995). Western blot analysis of proteins from HeLa cells exposed to DEM for different times shows that a fastermigrating (FM) band appears and accumulates together with the p21 form normally present in untreated cells (Figure 1A). This phenomenon is dependent on oxidative stress, considering that it is prevented by $\mathrm{N}$-acetylcysteine (NAC), a GSH-precursor that counteracts DEM effect by increasing GSH intracellular concentration (Figure 1B). The appearance

A

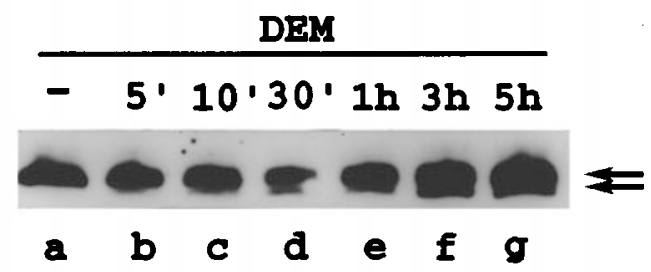

B

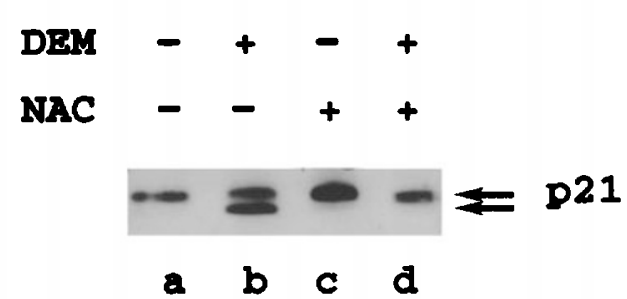

Figure 1 Oxidative stress induces the expression of a faster-migrating form of $\mathrm{p} 21$. (A) HeLa cells were exposed to $1 \mathrm{mM}$ DEM and harvested for protein extract preparation. The protein extracts were prepared as described in Materials and Methods and analyzed by Western blot with anti-p21 antibody. Lane $a$, untreated cells; lanes $b$ to $g$, cells treated with $1 \mathrm{mM}$ DEM for the indicated times. The two arrows indicate the two forms of p21. (B) HeLa cells were pretreated with $30 \mathrm{mM} \mathrm{NAC}$ for $1 \mathrm{~h}$ and then with $1 \mathrm{mM}$ DEM for $1 \mathrm{~h}$. The cellular extracts were analyzed by Western blot with anti-p21 antibody. Lane a, untreated cells; lanes $b$ and $d$, cells treated with DEM; lanes $c$ and $d$, cell treated with NAC. The two arrows indicate the two forms of p21 of the FM p21 form is very early, as demonstrated by the Western blot of Figure $1 \mathrm{~A}$ in which the FM p21 form is already present $5 \mathrm{~min}$ after DEM treatment; furthermore, the amount of FM p21 form is dose-dependent, and even very low doses of DEM $(250 \mu \mathrm{M})$ are able to induce its appearance (Figure 2A). On the contrary, TPA treatment that, analogously to DEM, induces p21 accumulation, never results in these cells in the appearance of the FM p21 form (Figure 2B).

An important point to be addressed concerns the molecular pathway through which DEM induces the appearance of the FM p21 form. We know that DEM induces the MAPK pathway, and this is necessary for the p53-independent p21 accumulation (Esposito et al, 1997). TPA, like DEM, provokes the activation of MAPK, but the resulting accumulation of p21 is always higher than that caused by DEM, probably because TPA acts also at a transcription level (Esposito et al, 1997; Biggs et al, 1996). In any case the appearance of the FM p21 form seems to be independent from the mechanism through which TPA or DEM induce the accumulation of p21. In fact, as shown in Figure 3 , the exposure to DEM of cells pretreated with TPA

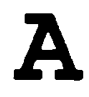

\section{DEM}
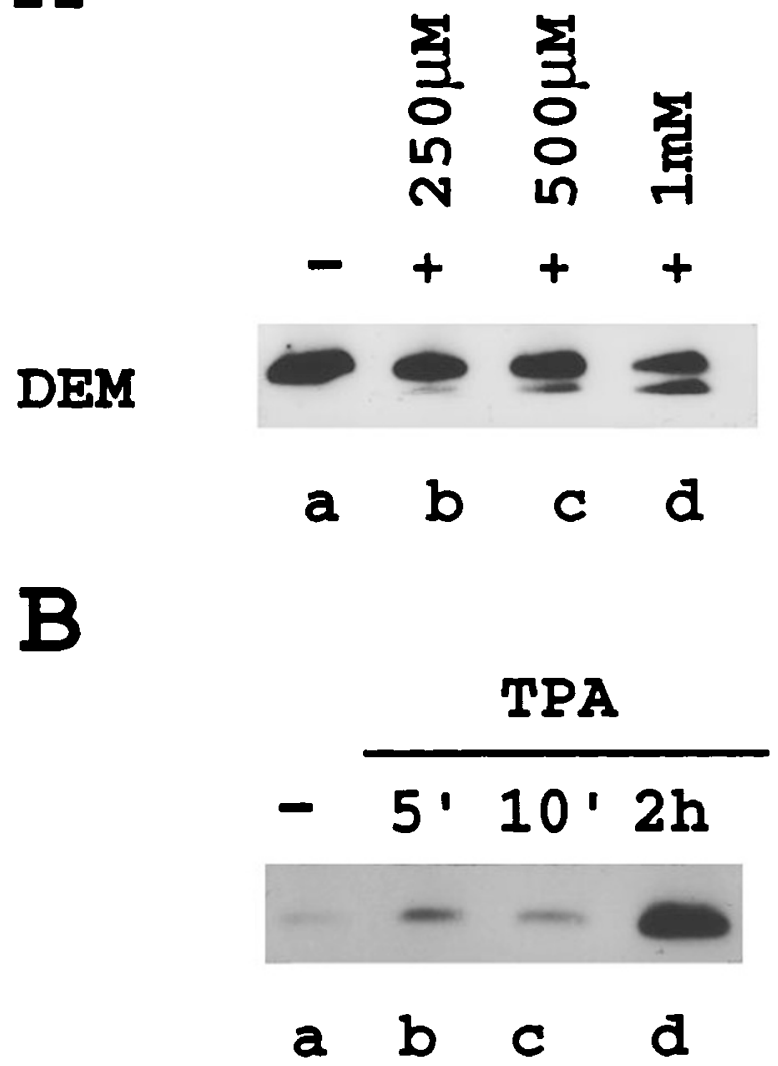

Figure 2 Effects of DEM and TPA treatments on p21 expression. (A ) HeLa cells were exposed to different concentrations of DEM for $30 \mathrm{~min}$ and harvested for protein extract preparation. Lane $a$, untreated cells; lane $b$, cells treated with $250 \mu \mathrm{M} \mathrm{DEM}$; lane c, cells treated with $500 \mu \mathrm{M} \mathrm{DEM}$; lane d, cells treated with $1 \mathrm{mM}$ DEM. (B) HeLa cells were treated with $50 \mathrm{ng} / \mathrm{ml}$ TPA and harvested for protein extract preparation. Lane a, untreated cell; lanes b to d, cells treated with $50 \mathrm{dng} / \mathrm{ml}$ TPA for the indicated times 
still induces the FM p21 form. To evaluate whether also the observed FM p21 is dependent on the activation of MAPK, a dominant negative mutant of MEK (Cowley et al, 1994), the kinase responsible for MAPK phosphorylation and activation, was transfected in COS7 cells. To control the effectiveness of MAPK inhibition caused by the overexpression of $\mathrm{MEK}^{-}$mutant, we evaluated the effect of DEM treatment in cells transiently transfected with the $\mathrm{MEK}^{-}$vector. As shown in Figure 4 the transient transfection of $\mathrm{MEK}^{-}$prevents the DEM-induced activation of MAPK (Figure 4B). On the contrary overexpression of $\mathrm{MEK}^{-}$does not affect the DEM-dependent appearance of FM p21 form (Figure 4A), thus suggesting that this phenomenon is MAPK-independent.

The difference between the electrophoretic migration of the slower- and faster-migrating p21 forms could be a consequence of different molecular mechanisms: (i) posttranslational processing of the SM p21 consisting in a protease-mediated excision of a part of the molecule or on the existence of alternatively spliced forms of p21 mRNA; (ii) post-translational modifications (e.g. phosphorylation) of the SM p21 form which could be absent in the FM p21 form. It was recently observed that in some cell lines TPA treatment induces the appearance of a faster-migrating form of p21 protein. In those cases it was suggested that this could be the result of a proteolytic processing or of a different post-translational modification of the C-terminal domain of p21 (Tchou et al, 1996). To discriminate between these two hypotheses, we generated a construct in which the CMV promoter drives the expression of a recombinant protein consisting of the whole p21 molecule fused at the C-terminus to a hemoagglutinin epitope recognized by an anti-HA antibody. If the FM p21 form results from the protease-mediated $\mathrm{C}$-terminal processing, the recombinant FM p21-HA protein would lose the HA tag, therefore it can not be seen with an anti-HA antibody. The result of this experiment shows that in cells transfected with the CMVp21-HA vector, the FM band of the recombinant p21-HA is still present following a $30 \mathrm{~min}$ DEM treatment, as demonstrated by the Western blot with anti-HA antibodies

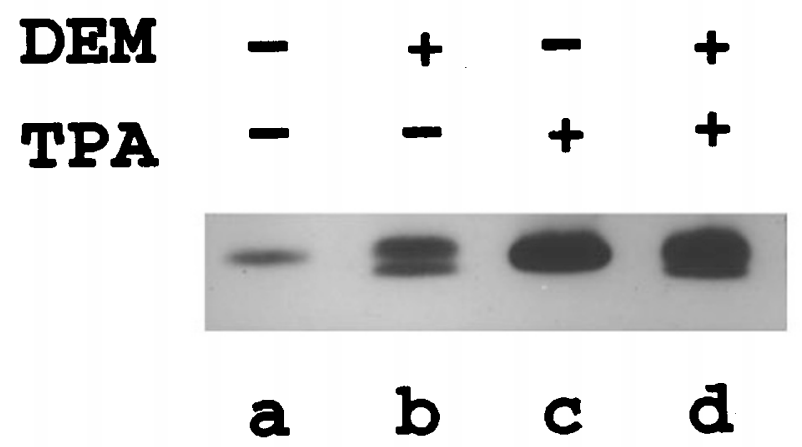

Figure 3 Effects of the concomitant exposures to DEM and TPA on p21 expression. HeLa cells were treated with $1 \mathrm{mM}$ DEM and/or with $50 \mathrm{ng} / \mathrm{ml}$ TPA Lane a, untreated cells; lane b, cells treated with DEM for $1 \mathrm{~h}$, lane cells treated with TPA for $2 \mathrm{~h}$; lane $\mathrm{d}$, cells treated with TPA for $1 \mathrm{~h}$ and then exposed to DEM for $1 \mathrm{~h}$
(Figure 5). Therefore, the DEM-induced FM form does not result from a proteolytic excision of the C-terminal region.

Considering that alternative splicing of p21 mRNA have never been described, the most likely hypothesis concerns the possibility that SM and FM p21 forms are differently modified. It was reported that p21 is phosphorylated at least at the level of serines 98 and 130 (Zhang et al, 1994). If DEM treatment affects these phosphorylation events, it could work by inhibiting kinase activities responsible for p21 phosphorylation or by activating specific phosphatases. To discriminate between the two possible mechanisms responsible for the appearance of the FM p21 form (i.e. inhibition of kinase(s) or activation of phosphatase(s)) we performed two experiments. In the first one HeLa cells were treated with cycloeximide to block protein synthesis. If FM p21 represents newly synthesized p21 not yet phosphorylated, the cycloeximide block of translation would result in the abolishment of the faster-migrating form following DEM exposure. Figure 6 shows that the FM form is still present after the block of protein synthesis, thus demonstrating that the appearance of FM p21 is independent from the de novo

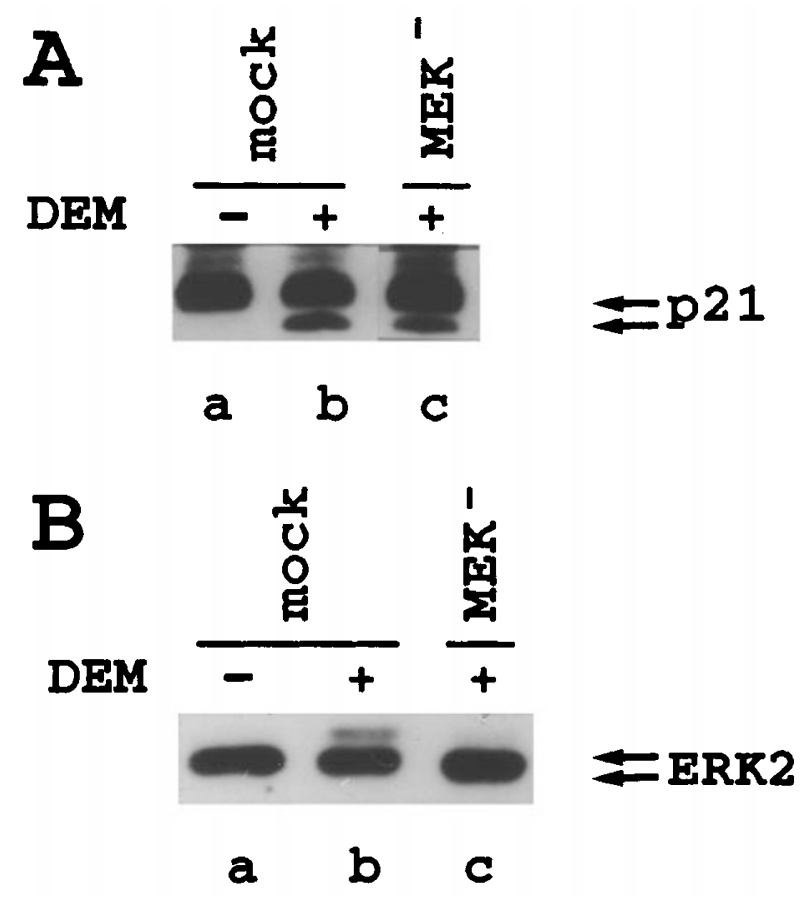

Figure 4 The appearance of the faster-migrating p21 form is independent on MAPK activation. COS 7 cells were transfected, as described in Materials and Methods, with plasmid vectors expressing $\mathrm{MEK}^{-}$dominant negative mutant, under the control of a constitutive promoter, or with the empty vector (mock). Forty-eight hours after transfection cells were exposed to $1 \mathrm{mM} \mathrm{dEM} \mathrm{for} 30 \mathrm{~min}$ and then harvested for protein extract preparation as described in Materials and Methods. Protein extracts were in lanes $a$ and $b$ from mock-transfected cells; in lane c from cells transfected with $\mathrm{MEK}^{-}$dominant negative mutant; protein extracts from cells treated with DEM were analyzed in lanes $b$ and $c$. (A) the protein extracts were analyzed by Western blot with anti-p21 antibodies, the two arrows indicate the two forms of p21. (B) the same protein extracts were analyzed by Western blot with anti-ERK2 antibodies, the upper arrow indicates the phosphorylated (activated) form of MAPK, whereas the lower arrow indicates non-phosphorylated form of MAPK 
protein synthesis and that it is the result of the modification of the preexisting protein. This result is compatible with the hypothesis of a DEM-induced activation of p21 dephosphorylation, while it is conflicting with the other hypothesis, i.e. the DEM-induced inhibition of p21 phosphorylation. To evaluate whether DEM can induce the observed phenomenon through the activation of phosphatases acting on phosphorylated SM p21, we exposed cells to okadaic acid, an inhibitor of phosphatases, prior to DEM treatment. As shown in Figure 7 this experimental condition leads to a lower level of FM p21 compared to that observed in cells treated with DEM alone. Similarly, the exposure of cells to DEM followed by okadaic acid treatment allows to observe the same decrease in the amount of the FM p21 band compared to cells treated only with DEM. These results, then, support the hypothesis that the FM p21 band is due to the dephosphorylation of p21.

Another important point to be addressed concerns the specific functional role of the FM p21 form. p21 interacts with and inhibits cyclin/cdk complexes, and in turn it blocks cell-cycle progression driven by these enzymes (Harper et al, 1993; El-Deiry et al, 1993; Xiong et al, 1993). p21 also interacts with PCNA, which is an auxiliary factor of DNA polymerases, inhibiting PCNA-dependent DNA replication (Flores-Rozas et al, 1994) but leaving unaffected the ability of PCNA to activate DNA repair ( $\mathrm{Li} \mathrm{R}$ et al, 1994). The domains of p21 involved in the interaction with these proteins have been fully characterized (Goubin and Ducommun, 1995; Chen I-T et al, 1996) and the two phosphorylated serine residues (S98 and S130) are not included in the interaction domains. In any case, conversion of these two serines into alanines does not inhibit p21-cdk complex formation and does not affect the ability of p21 to inhibit cdk activity (Zhang et al, 1994).

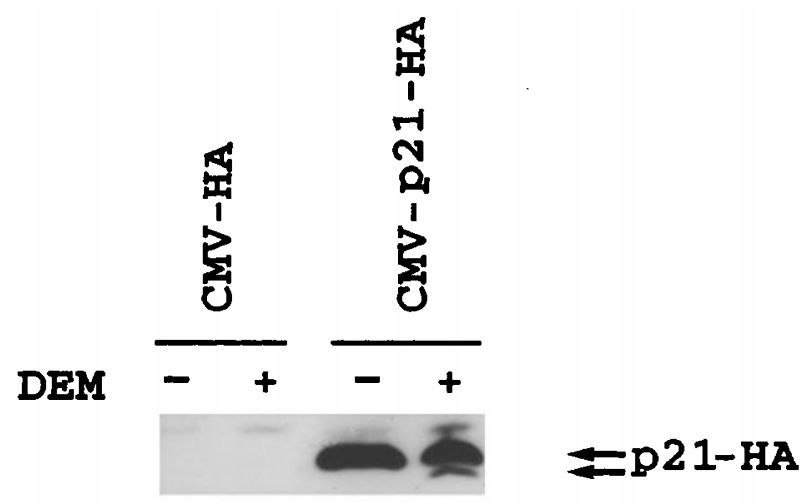

$\begin{array}{llll}a & b & c & d\end{array}$

Figure 5 DEM-induced modification of p21 is not a proteolytic truncation of p21. COS 7 cells were transfected, as described in Materials and Methods, with a vector expressing a chimeric p21-HA protein under the control of the CMV promoter. Forty-eight hours after the transfection the cells were exposed to $1 \mathrm{mM}$ DEM for $30 \mathrm{~min}$ and then harvested for cellular extract preparation as described in Materials and Methods. The protein extracts were analyzed by Western blot with an antibody against the HA epitope. Lanes a and b, cells transfected with the control vector (CMV-HA); lanes $c$ and $d$, cells transfected with the vector expressing the recombinant p21-HA protein (CMV-p21-HA); lanes $b$ and $d$, cells treated with DEM

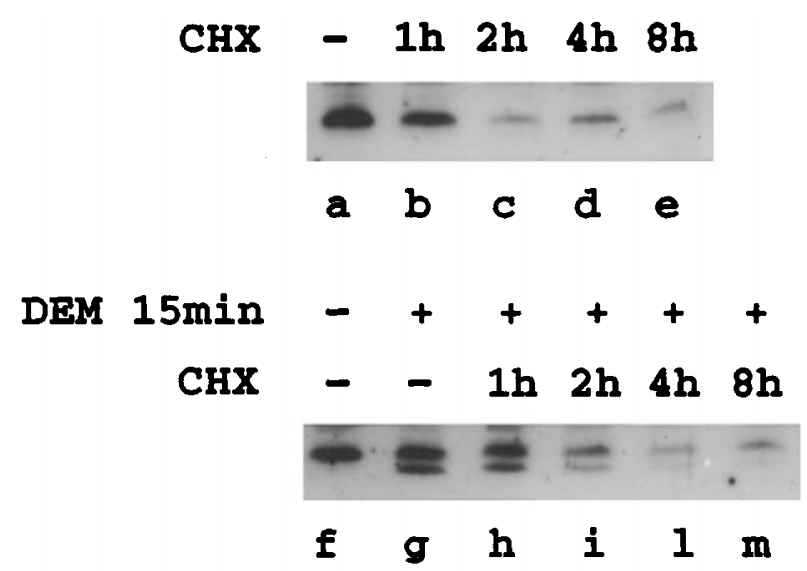

Figure 6 DEM-induced faster-migrating form of p21 is not dependent upon newly synthesized proteins. HeLa cells were exposed to cycloeximide $(12 \mu \mathrm{g} /$ $\mathrm{ml}$, lanes $\mathrm{b}$ to $\mathrm{e})$ or before to cycloeximide and then to DEM (1 mM) for $15 \mathrm{~min}$ (lanes $\mathrm{h}$ to $\mathrm{m}$ ) and harvested for protein extract preparation as described in Materials and Methods. Lane a, untreated cells; lanes $b-e$, cells exposed to cycloeximide for the indicated times; lane f, untreated cells; lane $\mathrm{g}$, cells treated with DEM for $15 \mathrm{~min}$; lanes $\mathrm{h}-\mathrm{m}$, cells treated with cycloeximide for the indicated times and then with DEM for $15 \mathrm{~min}$

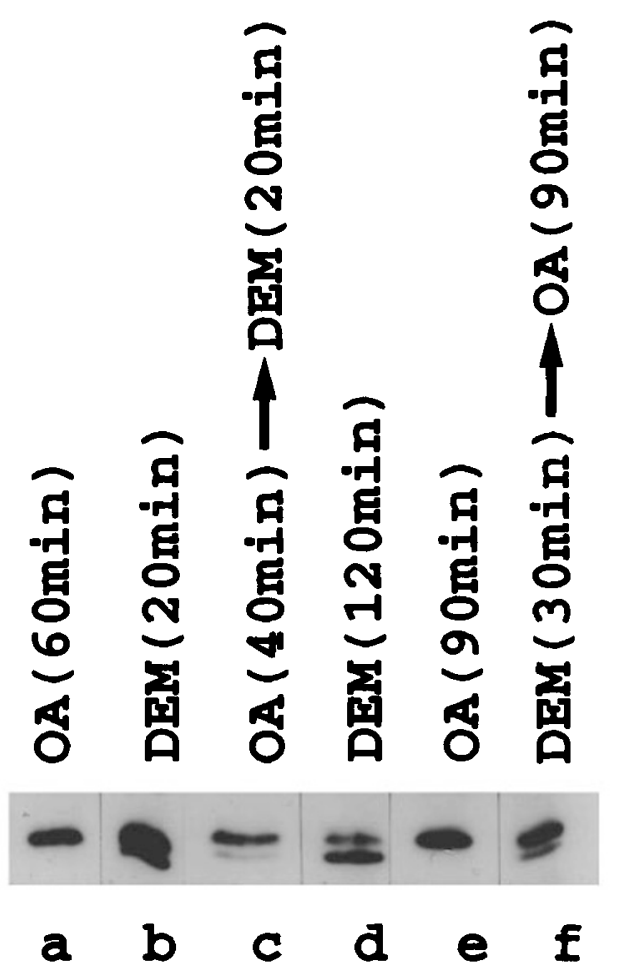

Figure 7 Effect of phosphatase inhibition on the appearance of the fastermigrating form of p21 induced by DEM. HeLa cells were exposed to $50 \mathrm{ng} / \mathrm{ml}$ okadaic acid (OA) and to $1 \mathrm{mM} D E M$ and then harvested for protein extract preparation as described in Materials and Methods. Lane a, cells exposed to OA for $60 \mathrm{~min}$; lane b, cells exposed to DEM for $20 \mathrm{~min}$; lane c, cells exposed to OA for $40 \mathrm{~min}$ and then to DEM for $20 \mathrm{~min}$; lane d, cells exposed to DEM for $120 \mathrm{~min}$; lane $e$, cells exposed to $O A$ for $90 \mathrm{~min}$; lane $f$, cells previously exposed to DEM for $30 \mathrm{~min}$ and then to $\mathrm{OA}$ for $90 \mathrm{~min}$ 
As mentioned above, the occurrence of a faster migrating p21 form was already described in Calu-1 cells treated for $24 \mathrm{~h}$ with high doses of TPA $(10 \mathrm{nM})$, but not with low $(1 \mathrm{nM})$ doses (Tchou et al, 1996). An interesting observation made by these authors concerns the association of the appearance of the p21 faster migrating band with the induction of a G2/M arrest. In fact, $1 \mathrm{nM}$ TPA treatment induces an increase in the number of cells in G1, whereas $10 \mathrm{nM}$ TPA treatment leads to an accumulation of cells both in G1 and in G2/M (Tchou et al, 1996). On the contrary, U937 cells, in which TPA treatment does not cause the appearance of the p21 faster migrating band, were arrested only in G1. The overexpression of oncogenic ras in primary or immortalized fibroblasts leads to the accumulation of p21 and the presented blot clearly shows also a p21 faster-migrating band (Serrano et al, 1997). Also in this case an increase of cells blocked in $\mathrm{G} 1$, but also in $\mathrm{G} 2 / \mathrm{M}$, can be observed. These results are interestingly in agreement with our previous results indicating that DEM treatment provokes an accumulation of T98G cells either in G1 or in G2/M phases (Russo et al, 1995). In fact, at low DEM concentrations (250 and $500 \mu \mathrm{M})$ a clear increase of the cell number in G2/M, with a concomitant decrease of cells in $\mathrm{G1}$, was seen. Considering that the accumulation of p21 is almost undetectable at $250 \mu \mathrm{M}$, whereas the appearance of FM p21 is an early event also at this low DEM concentration (Figure 2A), one could consider the possibility that FM p21 can affect cell cycle progression at G2/M phases. It is worth noting that a possible role of p21 in regulating cell cycle progression also during G2/M phases was suggested by the observation that p21 mRNA shows two peaks during the cell cycle in synchronized fibroblasts, during $\mathrm{G} 1$ and during G2/M ( $\mathrm{Li} \mathrm{Y}$ et al, 1994).

In order to understand the role of this FM p21 form, experiments are in progress, using site-directed mutagenesis, to evaluate the role of the post-translational modifications of p21 in inducing either G1 or G2/M arrest following oxidative stress. On the other hand, several results indicate that reactive oxygen species could be involved, as intracellular second messengers, in the regulation of early responses to the activation of growth factor receptors (Sundaresan et al, 1995; Irani et al, 1997) and in the p53-induced growth arrest and/or apoptosis (Polyak et al, 1997). The appearance of FM p21 even at low doses of DEM and after a short lag from the exposure to the drug suggests further experiments to ascertain whether this phenomenon plays a role as a regulator of cell cycle progression.

\section{Materials and Methods}

\section{Cell lines and materials}

HeLa and COS7 cell lines (purchased from American Type Culture Collection) were cultured in Dulbecco's modified Eagle's medium (DMEM) containing 10\% fetal calf serum (CS, ICN), 100 units $/ \mathrm{ml}$ penicillin and $100 \mathrm{mg} / \mathrm{ml}$ streptomycin at $37^{\circ} \mathrm{C}$ in a $5 \% \quad \mathrm{CO}_{2}$ atmosphere. Anti-p21 polyclonal antibody was from Santa Cruz
Biotechnology. Anti-hemoagglutinin (HA) antibody was from Boehringer. DEM, N-acetylcysteine (NAC), TPA and okadaic acid (OA) were from Sigma: DEM was added directly to the culture medium into the dishes from the concentrated solution at $1 \mathrm{mM}$ final concentration; NAC was dissolved in phosphate buffered saline solution at a final concentration of $30 \mathrm{mM}$; TPA and OA were both used at a final concentrations of $50 \mathrm{ng} / \mathrm{ml}$. Cycloeximide (Sigma) was used, alone or with DEM, at a final concentration of $12 \mu \mathrm{g} / \mathrm{ml}$.

\section{Plasmids and transfections}

The plasmid pBABE LIDA (MEK ${ }^{-}$), expressing a dominant negative mutant of MAPK kinase (MEK) was kindly provided by Dr. Marshall (Cowley et al, 1994). To ascertain whether or not the faster migrating band induced by DEM treatment was dependent on the proteolytic truncation of its C-terminus, an expression vector was generated which drives the expression of a chimeric protein encoded by the translated region of the p21 cDNA fused, at its $3^{\prime}$ end, before the stop codon, to a hemoagglutinin tag-encoding oligonucleotide. To do this, the p21 cDNA was amplified by using as upstream primer the oligonucleotide 5'GCGGAAGCTTATGTCAGAACCGGCTGGGGAT3', that was designed on the basis of the p21 cDNA sequence encoding the first seven residues of the protein. The downstream primer contains 27 nucleotides complementary to a sequence encoding nine amino acids of $\mathrm{HA}$ recognized by the anti-HA antibody, followed by 21 nucleotides encoding the last seven residues of p21 (GCGGAGTAGCGGCCGCTTAAGCGTAATCTGGAACATCATATGGGTAGGGCTTCCTCTTGGAGAAGAT). The resulting amplified product was cloned into the RC-CMV plasmid (Invitrogen) and transfected into COS7 cells by electroporation (Bio-Rad gene pulser). Cells were then exposed to DEM for the indicated time and the recombinant p21-HA protein synthesized by the cells was analyzed by Western blotting using the anti-HA antibody.

\section{Western blot analysis}

Protein extracts were obtained by lysing the cells on ice in a buffer containing $1.6 \mathrm{mM} \mathrm{KH}_{2} \mathrm{PO}_{4}, 12.5 \mathrm{mM} \mathrm{K}_{2} \mathrm{HPO}_{4}, 1 \%$ Tryton, $3.4 \mathrm{mM}$ SDS, $0.1 \mathrm{M} \mathrm{NaCl}, 11.5 \mathrm{mM}$ Na-deoxycholate, $0.1 \%$ sodium azide, $50 \mathrm{mM}$ sodium fluoride, $1 \mathrm{mM}$ sodium orthovanadate, $10 \mathrm{mM}$ sodium pyrophosphate and $1 \mathrm{mM}$ phenylmethylsulfonyl fluoride. Soluble extracts used for Western blots were obtained by centrifuging the lysate at $4^{\circ} \mathrm{C}$ at $1000 \times g$ for $10 \mathrm{~min}$; the resulting supernatant was analyzed by the Bradford method (Bio-Rad) for protein determination, and $50 \mu \mathrm{g}$ amount of proteins were loaded and electrophoresed through a $15 \%$ SDS-polyacrylamide gel and then transferred to Immobilon-P transfer membranes (Millipore); the incubation with antip21 antibody was performed for $12 \mathrm{~h}$ at $4^{\circ} \mathrm{C}$, while the incubation with anti-HA was according to the manufacturers. MAPK activity was assayed as elsewhere described (18) by a Western blot with polyclonal anti-MAPK Ig (ERK2, Santa Cruz). After incubation with rabbit horseradish peroxidase-conjugated secondary antibody, the blots were developed using enhanced chemiluminescence (Amersham).

\section{Acknowledgements}

This work was supported by grants from Italian National Research Council (CNR) PF 'Biotecnologie' and 'Invecchiamento', from Associazione Italiana per la Ricerca sul Cancro (AIRC), and from Ministero dell'Università e della Ricerca Scientifica e Tecnologica (MURST). 


\section{References}

Biggs JR, Kudlow JE and Kraft AS (1996) The role of the transcription factor Sp1 in regulating the expression of the WAF1/CIP1 gene in U937 leukemic cells. J. Biol. Chem. 271: $901-906$

Chen J, Jackson PK, Kirschner MW and Dutta A (1995) Separate domains of p21 involved in the inhibition of cdk kinase and PCNA. Nature 374: 386-388

Chen J, Saha P, Kornbluth BD, Dynlacht BD and Dutta A (1996) Cyclin binding motifis are essential for the induction of $p 21^{\mathrm{CIP} 1}$. Mol. Cell. Biol. 16: 4673-4682

Chen I-T, Akamatsu M, Smith ML, Lung FT, Duba D, Roller PP, Fornace Jr AJ and O'Connor PM (1996) Characterization of p21 $1^{\text {Cip } 1 / \text { Waf1 }}$ domains required for cyclin E/Cdk2 and PCNA interaction. Oncogene 12: 585-607

Cimino F, Esposito F, Ammendola R and Russo T (1997) Gene regulation by reactive oxygen species. In: Stadtman ER and ChockPB, (eds). Current Topics in Cellular Regulation Academic Press: S. Diego vol. 35 pp 123-148

Cowley S, Paterson H, Kemp P and Marshall CW (1994) Activation of MAPK is necessary and sufficient for PC12 differentiation and for transformation of NIH3T3 cells. Cell 77: $841-852$

El-Deiry WS, Tokino T, Velculesku VE, Levy DB, Parsons R, Trent JM, Lin D, Mercer WE, Kinzler KW and Vogelstein B (1993) WAF1, a potential mediator of p53 tumor suppression. Cell 75: 817-825

El-Deiry WS, Harper JW, O'Connor PM, Velculescu VE, Canman CE, Jackman J, Pietenpol JA, Burrel M, Hill DE, Wang Y, Wiman KG, Mercer WE, Kastan MB, Kohn KW, Elledge SJ, Kinzler KW and Vogelstein B(1994) Waf1/CIP1 is induced in p53-mediated g (1) arrest and apoptosis. Cancer Res. 54: 1169-1174

Esposito F, Cuccovillo F, Vanoni M, Cimino F, Anderson CW, Appella E and Russo T (1997) Redox-mediated regulation of $\mathrm{p} 21^{\text {waf } 1 / \mathrm{cip} 1}$ expression involves a posttranscriptional mechanism and activation of the mitogen-activated protein kinase pathway. Eur. J. Biochem. 245: 730-737

Flores-Rozas H, Kelman Z, Dean FB, Pan Z-Q, Harper JW, Elledge SJ, O'Donnell M and Hurvitz J (1994) Cdk-interacting protein 1 directly binds with proliferating cell nuclear antigen and inhibits DNA replication catalyzed by the DNA polymerase $\delta$ holoenzyme. Proc. Natl. Acad. Sci. USA 91: 8655-8659

Goubin F and Ducommun B (1995) Identification of binding domains on the p21 Cip1 cyclin-dependent kinase inhibitor. Oncogene 10: 2281-2287

Gulbis JM, Kelman Z, Hurwitz J, O'Donnel M and Kuriyan J (1996) Structure of the Cterminal region of $\mathrm{p} 21^{\text {waf1/cip } 1}$ complexed with human PCNA. Cell 87: 297-306

Harper JW, Adami GR, Wei N, Keyomarsi K and Elledge SJ (1993) The p21 Cdkinteracting protein $\mathrm{Cip} 1$ is a potent inhibitor of $\mathrm{G} 1$ cyclin-dependent kinases. Cell 75: $805-816$

Irani K, Xia Y, Zweier JL, Sollt SJ, Der CJ, Fearon ER, Sundaresan M, Finkel T and Goldschmidt-Clermont PJ (1997) Mitogenic signaling mediated by oxidants in ras-transformed fibroblasts. Science 275: $1649-1652$
Li R, Waga S, Hannon GJ, Beach D and Stillman B (1994) Differential effects by the p21 CDK inhibitor on PCNA-dependent DNA replication and repair. Nature 371: $534-537$

Li Y, Jenkins CW, Nichols MA and Xiong Y (1994) Cell cycle expression and p53 regulation of the cyclin-dependent kinase inhibitor p21. Oncogene 9: $2261-$ 2268

Liebermann DA, Hoffman B and Steinman RA (1995) Molecular controls of growth arrest and apoptosis: p53-dependent and independent pathways. Oncogene 11: $199-210$

Macleod KF, Sherry N, Hannon G, Beach D, Tokino T, Kinzler K, Vogelstein B and Jacks $T$ (1995) p53-dependent and independent expression of p21 during cell growth, differentiation, and DNA damage. Genes \& Dev. 9: 935-944

Michieli P, Chelid M, Lin D, Pierce JH, Mercer WE and Givol D (1994) Induction of WAF1/CIP1 by a p53-independent pathway. Cancer Res. 54: $3391-3395$

Plummer JL, Smith BR, Sies H and Bend JR (1981) Chemical depletion of glutathione in vivo. Meth. Enzym. 77: 50-59

Polyak K, Xia Y, Zweier JL, Kinzler KW and Vogelstein B (1997) A model for p53 induced apoptosis. Nature 389: 300-305

Russo T, Zambrano N, Esposito F, Ammendola R, Cimino F, Fiscella M, Jackman J, O'Connor PM, Anderson CW and Appella E (1995) A p53-independent pathway for activation of WAF1/CIP1 expression following oxidative stress. J. Biol. Chem. 270: $29386-29331$

Saeed Sheikh M, Li X-S, Chen J-C, Shao Z-M, Ordonez JV and Fontana JA (1994) Mechanisms of regulation of WAF1/CIP1 gene expression in human breast carcinoma: role of p53-dependent and independent signal transduction pathways. Oncogene 9: 3407-3415

Serrano M, Lin AW, McCurrach ME, Beach D and Lowe SW (1997) Oncogenic ras provokes premature cell senescence associated with accumulation of p53 and p16 ${ }^{\text {INK4a }}$. Cell 88: 593-602

Sundaresan M, Yu ZX, Ferrans J, Irani K and Finkel T (1995) Requirement for generation of $\mathrm{H}_{2} \mathrm{O}_{2}$ for platelet-derived growth factor signal transduction Science 270: 296-299

Tchou W-W, Rom WN and Tchou-Wong K-M (1996) Novel form of p21 WAF1/CIP1/ SDI1 protein in phorbol ester-induced $\mathrm{G}_{2} / \mathrm{M}$ arrest. J. Biol. Chem. 271: $29556-$ 29560

Xiong Y, Hannon GJ, Zhang H, Casso D, Kobayashi R and Beach D (1993) p21 is a universal inhibitor of cyclin kinases. Nature 366: 701-704

Zhang H, Hannon GJ and Beach D (1994) p21-containing cyclin kinases exist in both active and inactive states. Genes Dev. 8: 1750-1758

Zeng Y-X and El-Deiry WS (1996) Regulation of p21 WAF1/CIP1 expression by p53independent pathways. Oncogene 12: 1557-1564 